\title{
A didática da história e o desafio de ensinar e aprender na formação docente inicial
}

History didactics and the challenge of teaching and learning for early-stage teacher education

\author{
Cristiani Bereta da Silva* \\ Luciana Rossato**
}

Resumo

O artigo apresenta questões relacionadas ao desafio de ensinar e aprender História na Educação Básica e como ele é enfrentado na formação docente inicial em História. Um conjunto de relatórios de estágio, planos e relatos de observação de aula, produzidos entre 2006 e 2012, servirá de base a nossa análise. Consideramos três ordens de questões que, embora em planos distintos, entrecruzam-se e complementam-se: a) elaboração de ideias históricas por crianças e jovens; b) como os acadêmicos, futuros professores de História, percebem e pensam a aprendizagem quando ensinam História; c) de que forma os cursos de Licenciatura têm enfrentado o desafio da aprendizagem. As questões apresentadas, suportadas conceitualmente pela Didática da História, pretendem contribuir para adensar o debate sobre a aprendizagem

\section{Abstract}

This article presents issues related to the challenge of teaching and learning History within the sphere of basic education, as well as the way in which such challenge is faced in early-stage History teacher education. The basis for our analysis is comprised of a set of internship reports, classroom plans, and classroom observation sheets produced between 2006 and 2012. Three issue levels have been considered, albeit from different spheres, they intertwine and complement each other: a) elaborating historical ideas by children and youngsters; $b$ ) the way in which History students and future History teachers perceive and think of learning when teaching History; c) the way in which Teaching Programs have been facing the challenge of learning. Under the conceptual support of History Didactics, the presented issues intend to contribute to expanding the debate on History Teaching and Learning in basic

\footnotetext{
* Universidade do Estado de Santa Catarina (Udesc), Departamento de História. Programas de Pós-Graduação em História e em Educação. Bolsista Produtividade CNPq. Av. Madre Benvenuta, 2007. 88035-001 Florianópolis - SC - Brasil. cristianibereta@gmail.com

** Universidade do Estado de Santa Catarina (Udesc), Departamento de História. Programa de Pós-Graduação em História. Av. Madre Benvenuta, 2007. 88035-001 Florianópolis - SC - Brasil. lucianarossato@yahoo.com.br
} 
da História na Educação Básica e nos cursos de formação docente.

Palavras-chave: formação docente inicial; didática da História; ensino e aprendizagem. education, as well as in teaching education programs.

Keywords: early-stage teacher education; History didactic; teaching and learning.

Numa oficina realizada na turma 201, $2^{\circ}$ ano do Ensino Médio, na Escola de Educação Básica Padre Anchieta (Florianópolis/SC), um dos bolsistas do Programa Institucional de Bolsa de Iniciação à Docência (Pibid), acadêmico do curso de História da Universidade do Estado de Santa Catarina (Udesc), narrava uma situação de preconceito racial ocorrida recentemente com um amigo na Europa quando foi interrompido por um dos alunos que, sentado ao fundo da classe, perguntou indignado: "Ah, por que ele não deu um golpe de capoeira nele?".

A pergunta provocou risadas gerais e certo desconcerto no acadêmico, e logo outro aluno respondeu: "Isso não é novela, cara!". ${ }^{1}$

Esse pequeno trecho descreve uma situação bastante corriqueira no cotidiano de uma aula de História: o professor (nesse caso um acadêmico ainda em processo inicial de formação docente) recorreu a uma narrativa do presente, relacionada a uma experiência vivida, para iniciar uma aula em que pretendia problematizar preconceitos e discriminações no contexto do pós-abolição entre o final do século XIX e o início do século XX, no Brasil. Por sua vez, os alunos da classe dispuseram-se a discutir o que estava sendo tratado com base em referências também de seu cotidiano vivido - no caso em questão, referências de uma novela da Rede Globo que faz usos do passado. Essa oficina, parte das atividades do Pibid, foi realizada no dia 11 de setembro de 2012. No dia anterior, uma segunda-feira, estreara a novela 'das seis' Lado a Lado, ambientada no início do século XX, e uma das cenas principais do primeiro capítulo havia se desenvolvido justamente sobre o tema relativo à discriminação racial e à capoeira.

Escolhemos esse exemplo para introduzir as questões deste artigo porque evidencia o quanto História conhecimento e história vivida apresentam-se difusas no ambiente da sala de aula. Didaticamente o recurso de buscar referências no presente para introduzir temas históricos é estimulado na formação docente. Grosso modo entende-se que seria uma forma de aproximar a criança 
ou o adolescente das muitas vezes áridas questões contidas nas narrativas dos processos históricos distantes temporalmente e espacialmente do cotidiano dos estudantes. Isso porque sabe-se que em termos cognitivos a compreensão de causas e efeitos é favorecida quando aproximamos o sujeito do objeto a ser conhecido - na situação aqui narrada, relações sociais e de poder no Brasil, no final do século XIX. Ensinar fenômenos históricos tão complexos quanto esse só não é mais difícil que aprendê-los... Desculpem não estarmos separando esse processo tão indissociável quanto ensino e aprendizagem, é apenas uma estratégia para explicitar o quanto o processo de ensinar aparece turvando e até ocultando o aprender nas representações construídas pelos nossos alunos - futuros professores de História - quando eles pensam o ensino de História escolar. E isso ocorre não apenas com nossos alunos, para sermos sinceras. Em diferentes momentos, observamos essa dimensão nas falas de colegas que trabalham tanto na Educação Básica quanto no Ensino Superior, e muito provavelmente ela está contida até mesmo em nossa própria atuação como professoras de História.

A despeito disso, aprendemos história o tempo todo, ela é componente inescapável da configuração de nossa existência no tempo e no lugar do mundo que habitamos e do qual nos identificamos como pertencentes. Mas a história como uma forma de ver o mundo é diferente da História disciplina, assim como são diferentes os modos pelos quais acessamos o passado e o significamos. Aliás, o passado possui distinções que importam para se pensar o aprendizado da história. Peter Lee aponta, em "Por que aprender História", as imbricações e tênues fronteiras existentes entre o passado histórico e o passado prático na pesquisa e no ensino da História escolar. Com base no argumento de Michael Oakeshott, Lee lembra que o passado prático reorganiza os acontecimentos para que estes possam contribuir para as sucessivas condições das ações dos sujeitos individuais e coletivos. Ao passo que a história "representa um interesse nos eventos do passado ... respeitando sua independência nas sucessões do tempo ou nos eventos do presente", o passado prático possuiria uma relação específica com o presente, que seria a de justificativa para a realização de determinadas ações. "Este é o passado usado pelo advogado, político ou sacerdote." O passado prático é habitado por eventos, personagens e lições exemplares, portanto, "na ausência da história o passado é apenas prático". ${ }^{2}$ 
Aproximar, juntar ou misturar elementos da história vivida ou mesmo da história como forma pública de conhecimento e da História disciplinar são estratégias que não se reduzem à sala de aula, uma vez que também participam da própria elaboração da consciência histórica dos sujeitos. Entendemos o conceito de consciência histórica como algo intrinsecamente ligado à necessidade de o ser humano se orientar temporalmente, ou melhor, de atribuir sentido a sua existência. Isso se faz tanto com base no tempo da história vivida quanto no tempo da história conhecimento. Nesse sentido, para Jörn Rüsen, a consciência histórica, assim como a memória, seria uma forma de discurso histórico, mas, apesar de ambos os conceitos cobrirem o mesmo campo, o tematizam de forma diferente. Consciência histórica, assim, seria uma forma específica de memória histórica e cognitivamente poderia ser descrita como uma forma de significar a experiência do tempo pela interpretação do passado, de modo a possibilitar a compreensão do presente e projetar o futuro. $^{3}$

O processo de aprendizado sobre o passado não ocorre somente em sala de aula, mas em diferentes espaços e das mais variadas formas, por diferentes meios, sejam eles localizados em programas de TV ou nas relações sociais, entre outros. Na sala de aula, é impossível saber onde acaba uma dessas dimensões da história e se inicia outra, uma vez que são muitas as vias que conectam a abordagem acadêmica a outras formas de estabelecer relações com o passado. Não por acaso essa questão adiciona ainda mais complexidade à formação de professores para a Educação Básica, pois não basta identificar os elementos que participam do aprendizado histórico - também, e especialmente, é necessário compreender o lugar que a História escolar ocupa nesse processo, no presente. Supõe-se que o ambiente da sala de aula - ou ao menos os processos educativos formais - deva contribuir para o aprendizado de conceitos históricos que permitam às crianças e aos jovens compreender os processos e contextos históricos do passado e do presente, bem como construir conhecimentos imprescindíveis a sua formação e atuação política.

Consideramos que se trata de questões-chave e de irrenunciável importância na formação docente inicial, e há alguns anos temos buscado tornar o estágio supervisionado um espaço qualificado para se pensar e discutir os processos cognitivos que participam da construção do pensamento histórico. Há que se pesar, porém, que a despeito dessas iniciativas ainda persiste a 
ideia - incrustada na tradição acadêmica - de que para ensinar História os acadêmicos precisam prioritariamente dominar os conteúdos históricos. Muitos colegas ainda acreditam e defendem que basta formar bons historiadores para que tenhamos bons professores de História. Resultam dessa tradição atribuições de significados (re)construídos pelos acadêmicos dos cursos de História sobre o lugar que as disciplinas que abordam teorias da aprendizagem - sejam elas referentes a Jean Piaget, Lev Vygotsky ou mesmo aquelas situadas na teoria da História, como as elaboradas por Jörn Rüsen - ocupam no currículo. Não é raro que eles critiquem e, muitas vezes, negligenciem essas disciplinas 'pedagógicas' quando fazem a avaliação do currículo do curso, ou mesmo quando buscam atribuir sentido às práticas do estágio supervisionado em suas narrativas escritas. Nossa experiência na formação dos professores para a Educação Básica nos permite afirmar que ainda damos mais atenção às metodologias de ensino e à seleção dos conteúdos históricos a serem ensinados e deixamos pouco espaço para o estudo e a compreensão dos sujeitos da aprendizagem e dos processos do aprender.

Este artigo pretende ser um exercício de reflexão em torno dessas questões que fazem parte do nosso cotidiano de trabalho. Para nós o desafio da aprendizagem na formação docente não poderia ser pensado sem considerar três ordens de questões que, embora em planos distintos, conectam-se e complementam-se em diferentes pontos:

- A elaboração de ideias históricas por crianças e jovens;

- Como os acadêmicos dos cursos de licenciatura percebem e pensam a aprendizagem quando ensinam História;

- De que forma os cursos de licenciatura têm enfrentado o desafio da aprendizagem na formação docente.

Buscaremos discutir essas questões com base em nosso cotidiano de trabalho, na condição de professoras que atuam na formação de outros professores. Nossa análise foi pautada no desenvolvimento do projeto de ensino e pesquisa $O$ pensamento histórico de crianças e adolescentes e o ensino de História na Educação Básica, desenvolvido no Departamento de História e Programas de Pós-Graduação em História e em Educação da Udesc desde 2008 e que está em sua segunda versão. Na primeira versão foi desenvolvido em atividades de extensão, pesquisa e ensino apoiadas pelo Prodocência/Capes realizado com 
acadêmicos do curso de História e professores da Educação Básica. O objetivo da proposta é articular o exercício da docência em História às atividades de ensino e pesquisa na Educação Básica. O trabalho é realizado em escolas da rede pública de Florianópolis. A partir de junho de 2011, o projeto passou a ser desenvolvido em duas escolas, especificamente como subprojeto Pibid/ Capes - área de História - com concessão de 18 bolsas para acadêmicos e duas bolsas para professores da Educação Básica. As atividades de ensino e pesquisa são coordenadas pelas professoras titulares da disciplina de Estágio Supervisionado em História, Cristiani Bereta da Silva, Luciana Rossato e Nucia Alexandra Silva de Oliveira.

As disciplinas de Estágio Curricular Supervisionado historicamente produzem vasta documentação que traz percepções e representações sobre os processos que movem a dinâmica de uma sala de aula. São diversas narrativas escritas que possibilitam a compreensão da relação que os estudantes estabelecem com o ensino e a aprendizagem da História, em seu processo formativo. Isso porque, ao narrarem o espaço escolar, a prática docente, a história e seu ensino, os estudantes elaboram sentidos sobre a própria formação docente. Para nossa análise selecionamos alguns recortes dessas narrativas: projetos de estágio, comentários sobre as aulas ministradas, conclusões dos relatórios, artigos individuais, bem como relatórios de observação. Esse conjunto de narrativas escritas foi produzido pelos alunos das disciplinas Estágio Supervisionado I, II e III, ministradas na $5^{\mathrm{a}}, 6^{\mathrm{a}}$ e $7^{\mathrm{a}}$ fases respectivamente do curso de História da Udesc, entre 2006 e 2012. Esses recortes foram escolhidos porque são representativos de uma série que descreve práticas em sala de aula e impressões sobre esse processo. Neles buscamos identificar quais temas/ preocupações relacionados com a prática docente e a aprendizagem em História motivaram os acadêmicos, e como eles os analisaram em suas produções.

O exercício proposto é o de reflexão, e estamos cientes dos limites aí impostos. As questões apresentadas não servem à generalização, contudo podem contribuir para adensar o debate sobre a aprendizagem da História na Educação Básica e sobre o grau em que esse compromisso deve ser assumido pelos cursos de licenciatura em História. 


\section{DESLOCANDO O EIXO DA FORMAÇÃO DOCENTE:}

Nas últimas décadas as pesquisas realizadas no âmbito da Educação Histórica deslocaram o foco de 'o que deve ser ensinado' ou 'como se deve ensinar História na escola' para as operações cognitivas relacionadas ao desenvolvimento do pensamento histórico e da formação histórica de diferentes sujeitos. ${ }^{4}$ As questões tornadas pertinentes nesse contexto privilegiam a aprendizagem, ou seja, centram-se na análise de como crianças, jovens e adultos elaboram conhecimentos sobre a história. A investigação desse processo se dá num determinado contexto social e histórico, e seria a tarefa empírica da Didática da História. Para Klaus Bergmann, as pesquisas orientadas desse campo devem incluir entre os objetos de suas investigações as recepções extraescolares ou extracientíficas de história que atravessam o cotidiano e constituem o vivido dos indivíduos das mais diferentes formas. Entre esses objetos que influem na formação histórica estão a televisão, o cinema, a imprensa, as conversas cotidianas, os museus, a literatura histórica, as propagandas históricas, as representações científicas e populares sobre o passado, os livros didáticos, os monumentos, os edifícios e nomes de ruas que lembram eventos históricos, entre outros. ${ }^{5}$

No trabalho que temos desenvolvido na disciplina de Estágio Curricular Supervisionado, bem como nas atividades do Pibid, optamos por trabalhar com essa concepção da Didática da História que norteia nossas discussões relacionadas à formação docente. Vêm dela também nossas inserções relacionadas aos processos de ensinar e aprender História junto aos acadêmicos e aos professores envolvidos em nossa proposta. Embora tenhamos optado pelos referenciais da epistemologia da História para desenvolver nosso trabalho, importa notar que os demais estudos que fornecem suportes explicativos para o fenômeno da aprendizagem não são desconsiderados. Pesquisas relacionadas ao ensino e aprendizagem da História desenvolvidas com base nos pressupostos da Psicologia Cognitiva (principalmente aqueles relacionados aos estudos de Piaget e Vygotsky) servem de contraponto às nossas discussões com as turmas dos Estágios e também com o grupo do Pibid, ao mesmo tempo em que as complementam. 
Jörn Rüsen oferece uma discussão bastante instigante sobre as relações entre a História disciplina e outras formas e funções do conhecimento histórico. Seu trabalho nos fornece aportes teóricos que fundamentam o entendimento de que o ensino de História é apenas um dos fenômenos constituintes da formação histórica. Segundo Rüsen, existe todo um conjunto de processos de aprendizagem em História que atravessam a vida dos sujeitos e que não se destinam prioritariamente à obtenção de uma competência profissional específica, mas sim à orientação da vida prática, com base na consciência histórica. ${ }^{6}$ Essa perspectiva, em especial, amplia o horizonte de análise sobre o ensino de História, pois toma o sujeito como capaz de estabelecer sua própria relação com o mundo a que pertence, relação que é atravessada por percepções sobre o tempo histórico, perpassada por dimensões sobre o passado, o presente e o futuro.

Entendemos que numa formação docente de qualidade o ensino de História vai muito além de difundir conhecimentos sobre o passado e/ou contribuir para a formação de uma identidade nacional. Ensinar história nessa concepção estaria relacionado ao desenvolvimento da capacidade das crianças e dos jovens de pensar historicamente. Para isso, mais do que conhecer uma narrativa sobre o passado, entendemos que os alunos devem conhecer aspectos do processo de produção desse conhecimento. Isso significa desenvolver a capacidade de pensar o que ocorreu no passado com base no contato e na análise de diferentes evidências históricas e com isso construir uma narrativa histórica, com explicações provisórias e multidimensionais. A aprendizagem histórica adquire sentido na vida das pessoas porque decorre de questões e preocupações do presente, uma vez que o "saber histórico é um produto da experiência e da interpretação, resultado, pois, de síntese, e não um mero conteúdo pronto a ser decorado". ${ }^{7}$ Jörn Rüsen defende que o aprendizado histórico corresponde ao aumento da experiência, resulta em aumento da competência interpretativa e acarreta o aumento da capacidade de orientação, sendo essas três dimensões interligadas, afinal "não há experiência histórica livre de interpretação, nem orientação livre de experiência. Todo modelo de interpretação é relacionado simultaneamente à experiência e à orientação" (Rüsen, 2007, p.118). Para ele o ensino de História não pode ser centrado nem na aquisição de um determinado volume das informações disponíveis, nem somente nos interesses dos alunos. A saída deve ser um aprendizado histórico que estabeleça o equilíbrio entre a "história como dado objetivo nas circunstâncias da vida 
atual e a história como construto subjetivo da orientação prática movida pelos interesses" (Rüsen, 2007, p.120).

Aprender história não é somente acumular uma sequência de fatos e processos passados. $\mathrm{O}$ aprendizado histórico envolve apropriar-se de aspectos da epistemologia do fazer histórico, entre os quais a compreensão de conceitos do tempo, a identificação das evidências e de que estas são incompletas e limitadas, como são limitadas e provisórias as explicações históricas. Nessa perspectiva, ensinar História não se restringe a ensinar narrativas históricas elaboradas pelos historiadores e organizadas em uma lista de conteúdos previamente definidos. Ensinar História é algo mais complexo, é ensinar a capacidade de pensar historicamente. Para isso, além de conteúdos devem ser desenvolvidas habilidades cognitivas que visem possibilitar que os sujeitos conheçam e expliquem o mundo com base nas ferramentas próprias do conhecimento histórico. Segundo Lee, nos últimos 30 anos vem se desenvolvendo um debate entre duas posições diferentes, mas não excludentes, sobre a educação histórica no Reino Unido. Enquanto um grupo está preocupado em desenvolver a compreensão histórica, o outro está mais interessado no que os alunos sabem ou devem saber sobre o passado. $\mathrm{O}$ autor não vê conflito entre os dois interesses, mas ao se privilegiar o aprendizado do conteúdo o outro aspecto não é necessariamente desenvolvido ou mesmo acaba sendo negligenciado. ${ }^{8}$ Nesse sentido "saber história não é a mesma coisa que pensar historicamente correto, pois o conhecimento histórico apreendido apenas como algo dado não desenvolve a capacidade de conferir significados à história e orientar aquele que aprende de acordo com a própria experiência histórica". ${ }^{9}$

No entanto, essa concepção de aprendizagem em História é lacunar na experiência adquirida pela maioria dos graduandos de História no decorrer de sua formação escolar. Como as crianças e os jovens da Educação Básica, os graduandos que estão cursando História também possuem conhecimentos prévios sobre o passado e sobre o que significa "ser professor de história". Dessa forma, é imprescindível tomarmos consciência, na condição de formadores de futuros professores de História, sobre em quais aspectos da cultura escolar os graduandos estiveram imersos durante sua formação básica e mesmo universitária. Como salienta Maurice Tardif, "os saberes de um professor são uma realidade social, materializada através de uma formação, de programas, de práticas coletivas, de disciplinas escolares, de uma pedagogia 
institucionalizada etc., e são também os saberes dele". ${ }^{10}$ Esse aspecto também é analisado por Ana Maria Monteiro ${ }^{11}$ ao constatar que as experiências e os saberes dos professores de História influenciam sobremaneira suas escolhas nas práticas docentes. Nesse sentido, (re)significar essas experiências é fundamental para a reflexão sobre o fazer docente, e, especificamente para quem trabalha com a formação de professores de História, significa abrir espaço para que práticas sejam repensadas e talvez superadas.

\section{Concepções DE ENSINO E APRENDIZAGEM No EstágIo CURricular SUPERVISIONADO: O QUE PENSAM OS ESTAGIÁRIOS?}

O episódio relatado na abertura deste artigo aponta para singularidades envolvidas na formação inicial e relacionadas ao aprendizado histórico. Contudo, concordar em que aprendemos história nos mais variados lugares não significa prescindir da importância de se aprender História na escola. Nesse caso estamos relacionando a aprendizagem na Educação Básica com as noções relativas a esse processo postas em pauta na formação docente inicial. Certamente estamos falando de circunstâncias de aprendizados diferentes, os objetivos e finalidades do ensino e aprendizagem da História na Educação Básica são muito diferentes daqueles disponibilizados para os cursos de licenciatura em História, que se voltam à formação de um profissional da área. ${ }^{12}$ Para nós as questões relacionadas ao aprendizado se encontram justamente nas percepções que os acadêmicos do curso elaboram sobre o tema ao longo de seu processo formativo e que vão incidir em sua atuação na sala de aula, nas representações que constroem sobre as capacidades e os fenômenos que participam da elaboração das ideias históricas pelas crianças e pelos adolescentes.

Em sua discussão sobre o ensinar e aprender História na Educação Básica, Flavia Caimi foi muito feliz ao introduzir as questões sobre o tema por meio do seguinte provérbio: "para ensinar história a João é preciso entender de ensinar, de história e de João". ${ }^{13} \mathrm{Ou}$ seja, os processos de ensinar e aprender História estão implicados em três elementos indissociáveis, quais sejam: a especificidade da aprendizagem, a natureza da História e o sujeito que aprende. Parece-nos que, em certa medida, temos conseguido certo êxito no trabalho com a natureza da História, abordando as questões epistemológicas, teóricas e conceituais que sustentam esse campo de conhecimento. Contudo, em se 
tratando da especificidade da aprendizagem e, em especial, do sujeito que aprende, ainda há um longo caminho a percorrer. Isso porque estamos enredados no centramento da figura do professor, dos conteúdos e dos métodos que dimensionam o ensino e obliteram a aprendizagem.

Em nosso cotidiano de trabalho observamos que aspectos relacionados à natureza da História permanecem centrais na preocupação dos estudantes do curso em detrimento da especificidade da aprendizagem e do sujeito que aprende:

Uma avaliação superficial me faz pensar que ao aplicarmos um projeto de aulas, como pretendemos no próximo semestre, os alunos sentiriam grande dificuldade em acompanhar uma mudança no esquema habitual das aulas. Certamente isso não nos fará desistir e nem recuar quanto ao formato que pensamos, até porque em conversas com alguns deles, notamos alguma empolgação na formatação de um novo esquema de aulas ... Provavelmente o que contará ponto ao nosso favor, na atribuição das aulas, é que uma metodologia diferenciada tem grande chance de motivar os alunos aos estudos. Fica clara a falta de estímulo que os estudantes de nossa turma possuem ... O objetivo é proporcionarmos aos alunos uma abordagem diferente e mais estimulante no ensino da História, mesmo que por pouco tempo. ${ }^{14}$

Esse fragmento representa uma série de narrativas dos acadêmicos produzidas entre 2006 e 2012, na qual fica bastante evidente a ênfase nas metodologias de ensino e no próprio desenvolvimento das aulas, centrada na figura do professor. Esse centramento é observado em duas ordens: num primeiro momento no professor da turma, posteriormente na figura do estagiário. Mesmo a análise relativa ao interesse e à atenção das crianças e jovens na sala de aula é também realizada tomando-se por base esse centramento, como se pode observar nestes comentários:

Apesar do esforço de preparar a aula, vimos que não adianta chegar com muita coisa para dizer aos alunos, sem dar o devido tempo para que eles parem e assimilem tudo o que foi falado. Além disso, usar os dois períodos só falando é dificílimo para manter a atenção dos alunos presa, daí porque precisamos pensar em uma estratégia para mesclar atividades e aula expositiva. ${ }^{15}$

O que achamos mais marcante nas aulas foi a reação dos alunos com aulas mais expositivas, percebemos que não é um tipo de aula em que eles permaneçam mais 
calmos, com isso já optamos por algumas mudanças, a principal diminuir aulas desse tipo e incentivar mais debates entre os alunos. Importante ressaltar que a exposição sobre os personagens não teve tempo nas duas aulas da terça-feira e assim tivemos que continuar na quinta. Com isso, mais uma experiência, pois pecamos pelo excesso. Saímos dessa aula um pouco decepcionados por isso, mas essa 'decepção' nos fez buscar novas propostas de atividades, de aulas não apenas para agradar aos alunos, pois sabemos que há momentos em que é necessária aula expositiva, mas para permitir uma aula mais próxima das características da turma. ${ }^{16}$

Esse aspecto - aulas centradas no professor - também foi tomado como tema de reflexão pelo acadêmico Thiago Oliva de Araújo, quando explica, no início de seu artigo, a escolha por discutir o cinema em sala de aula. Segundo ele, um dos motivos foi o "vício do professor e da aula conteudista em que nós acadêmicos estamos submetidos". Essa opinião foi formada com base em sua experiência discente, que desde a Educação Básica até o Ensino Superior "contou com a atuação do professor como detentor da verdade e possuidor da informação privilegiada, do conhecimento especializado". Essa experiência o influenciou no momento em que esteve diante da turma de alunos pela qual ficou responsável durante seu estágio: "procurei transmitir aos alunos incontáveis informações históricas, buscando legitimar minha condição de professor". Ele relata, porém, que essa postura não gerou interesse e envolvimento dos alunos na aula, e os "resultados foram ordinários" ${ }^{17}$

Outra questão que chama atenção nos relatórios é a preocupação em vincular o que está sendo estudado com aspectos do presente, com a vida dos alunos. Esse é um recurso didático que aparece com frequência no cotidiano das aulas de História. Contudo, observamos também que localizamos a aprendizagem na compreensão de narrativas prontas, e não necessariamente na construção de processos cognitivos que desenvolvam capacidades autônomas e críticas de elaboração de novas concepções sobre a História, na elaboração de conhecimentos históricos:

Assim, com base no recorte sobre o conteúdo pensou-se o modo como este ia ser tratado, pensando em estabelecer um diálogo entre passado/presente, questionando-se principalmente sobre que sentido tal conteúdo poderia ter na vida dos alunos. Qual importância de tal conhecimento dentro, mas principalmente fora, dos muros da escola? E como fazer com que os estudantes compreendessem tanto a 
importância de conhecer sobre o conteúdo, quanto como aplicá-lo na prática, desenvolvendo uma leitura histórica e crítica da realidade presente em suas vidas? ${ }^{18}$

Era esta uma das nossas maiores preocupações: a de não desvincular os conteúdos da vida dos estudantes, pois, como já ouvimos e lemos diversas vezes ao longo do nosso curso, 'só fica o que significa'. Nesses 3 meses de estágio, buscamos trazer materiais distintos, fossem eles filmes, imagens e músicas, de forma a estimular a participação dos alunos. ${ }^{19}$

A preocupação em vincular a história ou o passado ao presente, a fim de tornar o aprendizado mais significativo para os jovens, é um aspecto muito marcante nos projetos de estágio. O grupo formado por Alexandre, Antonio, Filipe e Mariana constatou "o interesse dos alunos por temáticas que conectem o passado e o presente, em um sentido de analisar as repercussões do tempo passado na construção do tempo presente". ${ }^{20}$

Outra dimensão salientada é o envolvimento dos alunos nas atividades de análise de diversas fontes audiovisuais, imagéticas e escritas. O trabalho com fontes é um aspecto que tem sido desenvolvido nos estágios realizados no curso de história da Udesc:

A diversidade de fontes e a diversidade de discurso são importantes tendo em vista que os alunos são confrontados diariamente com informações diversas e/ou contraditórias e devem transformar tais informações em utilizáveis no seu dia a dia. Tendo essa questão em vista, e pensando que o professor é responsável por apresentar conhecimentos históricos prévios para suscitar a discussão, utilizaremos discussões em sala a fim de levantar questões acerca das multiplicidades da História e da historiografia a partir de diversas fontes. (Medeiros, 2012, p.28)

Procuraremos realizar diversas atividades visando não apenas transmitir fatos, datas e nomes, mas levantar discussões acerca do contexto e da utilização de fontes para ensinar história. (Gentil, 2012, p.24)

Uma preocupação que vem aparecendo nos relatórios dos estagiários, ainda que de forma muito incipiente, é a de identificar como os alunos aprendem, principalmente quando do relato e comentários referentes às atividades que não estão centradas no professor, como as oficinas de análise de fontes históricas:

Os estudantes compreendem que há a diversidade de documentos e as múltiplas explicações, mas não sabem como manusear isso a partir de uma análise especí- 
fica a cada documento. Apesar do gosto em discutir imagens e, principalmente, imagens em movimento, a maior dificuldade da turma está na análise desses materiais. (Medeiros, 2012, p.75)

Mas, enfim, o que foi possível perceber de mudança, tomando como parâmetro a primeira investigação que buscou as ideias prévias dos alunos? De uma maneira geral, os alunos conseguiram perceber que são múltiplos os discursos que podem ser construídos sobre um mesmo personagem, sejam esses discursos escritos, sejam, no nosso caso, imagéticos. E ainda mais importante, eles passaram a entender as imagens como fontes que também precisam ser questionadas, que não trazem em si a 'realidade' - principalmente no caso da fotografia. Foi notável a importância de se utilizar este tipo de abordagem [aula oficina com fontes] na aula de história, o que é ensinado parece adquirir mais sentido para os alunos, pois eles se inteiram, mesmo que de maneira superficial, do próprio ofício de historiador. $^{21}$

O professor do Departamento de Educação da Universidade de Estocolmo Olla Halldén, em seus estudos, detém-se sobre os limites e possibilidades relacionados à aprendizagem da História escolar. ${ }^{22}$ Em sua discussão fica claro que a noção de que os alunos precisam abandonar suas ideias prévias, suas próprias concepções em favor dos conceitos científicos, tidos como válidos, é passível de questionamentos, já há bastante tempo. Isso porque há diferentes planos relacionados às concepções sob o domínio do mundo do vivido e àquelas baseadas em conhecimentos científicos, pertencentes ao domínio simbólico. A aprendizagem efetiva ocorreria quando o aluno consegue relacionar esses dois domínios. Nesse aspecto é bastante central o protagonismo do professor de História, não mais como detentor de um conhecimento que será narrado, mas no sentido de que caberia a ele elaborar as estratégias relacionadas ao ensino a fim de compreender as ideias históricas que os alunos já possuem e, somente a partir daí, possibilitar formas variadas de construir situações em que as crianças e os jovens possam identificar os diferentes domínios e então relacioná-los.

Com base nos relatórios de estágio podemos identificar também os principais desafios encontrados pelos futuros docentes no seu trabalho. Um deles é a dificuldade de romper com a prática de aula centrada no professor e na aula expositiva. Outro é o distanciamento entre o que é estudado na universidade e o que é vivenciado na Educação Básica: 
O principal objetivo do estágio era interagir com o conhecimento prévio dos alunos acerca da identidade brasileira e dos fluxos migratórios vivenciados pelo país ao longo do século XIX. Em diversos momentos desviamos deste objetivo, substituindo esta interação pela exposição de conhecimento dado, pela metodologia mais segura e confortável, e nos perdemos em meio a um excesso de informação, com dificuldades para selecionar o que iríamos falar e mostrar durante as aulas. ${ }^{23}$

As aulas foram elaboradas com aporte teórico sobre o conceito de aulas oficinas e consciência histórica. Ambos caminham bem, juntos, um aplica o que o outro propõe, em tese. Porém, na prática a estrutura rígida escolar nos 'convida' à aula expositiva e por vezes sem diálogo! Sair deste padrão é difícil. Entrar em contato com os alunos diretamente e saber à medida que transpõe a autoridade do professor em autoritarismo é algo muito sutil ... Tentamos fugir de uma narração linear presa aos fatos passados, buscando uma ligação com os fatos da atualidade que estão no cotidiano dos alunos. ${ }^{24}$

Também refleti sobre a possibilidade de problematizar o abismo existente entre a Universidade, suas pesquisas intelectualizadas e seu vocabulário rebuscado, e a unidade escolar básica, a qual tem dinâmica particular e propõe a formação geral do indivíduo, a partir de bases preferencialmente críticas. O entrave entre as duas instituições fica evidente quando é preciso, por parte do professor do ensino básico, tornar didática a informação minuciosa e perspicaz que apreende na Universidade, que muitas vezes é abstrata, a discentes que naturalmente possuem capacidade de reflexão diferenciada. As inquietações que envolvem a vida de professor, seus desafios são demasiados. Logo, como transformar em texto articulado todas as sensações e reflexões experimentadas durante o decorrer do estágio? ${ }^{25}$

Uma das questões que mais têm chamado nossa atenção nessas narrativas produzidas durante o período de estágio (e que infelizmente pouco aparece no texto escrito) é a mudança de perspectiva em relação ao trabalho docente. Emoções diversas se completam: surpresa com a quantidade de conhecimentos e habilidades que envolvem o fazer docente, tristeza e decepção pelo que deu 'errado' e alegria por ter conseguido vencer as dificuldades e perceber que os alunos se envolveram nas atividades propostas e aprenderam alguma coisa.

O estágio foi, enfim, um lugar especial para as nossas primeiras visitas à sala de aula. Deu-nos a oportunidade de nos vermos como professores pela primeira vez. Ser chamado de professor, estranhar esse vocativo, ser convidado para explicar algo sobre a matéria ou sobre as perguntas, contar piadas para descontrair a 
turma, chamá-los para a discussão proposta, chamar a atenção em alguns momentos, resolver conflitos entre os alunos, dar as notas, corrigir provas, retorná-las aos alunos, ouvir algumas reclamações quanto às notas, escrever na lousa, ouvir que a sua letra não está legível, acordar mais cedo que o normal para dar aula, prepará-la, ficar amargurado por ela não ter ocorrido da forma que tinha sido planejada, replanejar no momento da aula, pedir para devolverem em outro dia a tarefa não terminada no tempo proposto, não devolverem a atividade no prazo marcado... Uma infinidade de relações de um cotidiano que só sendo professor para saber como é. Foi um momento divisor de águas, entre ser apenas aluno e ser aluno-professor. Uma dupla função muito interessante e instigante. Agora nos percebemos de outra maneira, diferente da qual no primeiro dia, ao entrar naquela sala de aula. (Gentil, 2012, p.147)

O primeiro contato com a sala de aula na condição de futuros professores é um momento que pode ser bastante difuso, pois a experiência se desenvolve numa dupla posição desses sujeitos: a de estudantes e também futuros professores. Quando passam a frequentar uma sala de aula pela primeira vez, os estudantes do curso de História não se reconhecem nem como estudantes colegas daqueles outros estudantes que ali estão nem ainda como professores. São sujeitos que habitam entre lugares, posições que envolvem desafios permeados por medos, desconfortos, afetos e sensibilidades difíceis de precisar e organizar até mesmo numa narrativa escrita. $\mathrm{O}$ conjunto de narrativas escritas incide sobre a própria formação histórica desses sujeitos, que, ao escreverem, atribuem sentido aos percursos e práticas docentes. Em razão disso esse material tem servido de base às nossas discussões junto às novas turmas que iniciam seu processo formativo no âmbito dos estágios. As mudanças são lentas, a despeito de nosso trabalho e esforço comprometido com uma formação docente de qualidade, mas existem.

\section{CONSIDERAÇÕES FINAIS}

No século XIX os objetivos consoantes à História escolar eram claros: um meio de instrução cívico-nacional, cujo fim principal era fortalecer o Estadonação ou legitimar a ordem social e política estabelecida, inculcando respeito e devoção aos cidadãos súditos. Ensinar significava ater-se às narrativas fundadoras dos eventos memoráveis e dos grandes personagens, e aprender era 
memorizar esse conjunto de acontecimentos que formariam uma memória comum. É Christian Laville quem aponta o quanto a história escolar mudou desde então em relação aos seus objetivos e pedagogias. No século XX, principalmente após a Segunda Guerra Mundial, os objetivos da história escolar se alteraram de modo importante e a ideia do cidadão-participante substituiria a do cidadão-súdito. Em seu lugar surgiria "uma pedagogia baseada no pensamento histórico, mais apropriada ao aprendizado das capacidades intelectuais e afetivas, necessárias ao exercício autônomo e competente de suas responsabilidades cívicas". ${ }^{26}$ Para Laville as capacidades que se espera empregar na construção do conhecimento histórico serão exercitadas pelos alunos tendo como base a variedade dos acontecimentos de sua realidade social, de seu cotidiano vivido e não necessariamente nas narrativas históricas aprendidas na escola. Na mesma direção, muito embora se concorde com a premissa de que é necessário aprender a pensar historicamente, poucos sabem como colocar em prática essa nova proposta. Sua crítica é de que as pesquisas relativas à Didática da História não produziram a ajuda esperada pelos professores no que se refere ao aprendizado do pensamento histórico; quando muito fornecem contribuições à compreensão histórica, ou seja, dois processos distintos. Enquanto o pensamento histórico diz respeito a um conjunto de operações intelectuais mobilizadas na produção dos saberes históricos, a compreensão histórica estaria envolvida no entendimento das intenções e dos pressupostos de uma narrativa já construída.

Entendemos que esses dois processos não são concorrentes e que mesmo ensinar a pensar historicamente é possível no ambiente da sala de aula, mesmo considerando os desafios aí envolvidos. Da mesma forma, se de fato ainda precisamos de pesquisas mais consistentes relativas ao aprendizado do pensamento histórico, nos termos explicitados por Laville, é inegável reconhecer as contribuições das pesquisas da área da Didática da História para uma melhor compreensão relativa aos aspectos cognitivos da elaboração das ideias históricas de crianças e jovens. Há mudanças importantes em relação à própria concepção de ensino e aprendizagem de História verificadas nas narrativas dos estagiários a partir de 2006, quando começamos efetivamente a desenvolver trabalhos relacionados à Didática da História no curso. Há permanências, claro, e os documentos produzidos pelos nossos estagiários deixam isso bem claro, mas pode-se dizer que houve também algum descentramento dos conteúdos de História e das 
metodologias de ensino que possibilitou a emergência de uma sensível preocupação com as ideias históricas das crianças e dos jovens.

Em entrevista recentemente concedida a uma das autoras deste artigo, ${ }^{27}$ o pesquisador e professor do Reino Unido Peter Lee descreve o quanto as pesquisas relacionadas ao desenvolvimento cognitivo vêm crescendo desde 1960 em diferentes países, e isso inclui o Brasil, cuja principal referência é o Laboratório de Pesquisa em Educação Histórica (Lapeduh) da Universidade Federal do Paraná (UFPR), que tem à frente a professora e pesquisadora Maria Auxiliadora Schmidt. Tal crescimento e o teor dessas pesquisas vêm ao encontro da constatação de que pouco avançaremos no ensino de História escolar e na própria formação de docentes para a Educação Básica se não considerarmos compreender a aprendizagem e os processos cognitivos envolvidos na elaboração das ideias históricas. A questão que nos parece premente é pensar nos objetivos relacionados ao ensino e à aprendizagem de História no presente e de como relacioná-los de modo qualitativo à formação docente.

É mais fácil pensar em metodologias e conteúdos de ensino do que nos processos de aprender, até porque são muitas as dificuldades relacionadas à aprendizagem da História na Educação Básica. Joaquín Prats apontou seis muito pertinentes, das quais destacamos:

- A compreensão da História supõe o uso de altos níveis de pensamento abstrato e formal;

- Ao contrário das chamadas ciências experimentais, como a Física ou a Química, por exemplo, é impossível reproduzir os fatos do passado para melhor exemplificá-los aos estudantes;

- Na área da História não há um vocabulário conceitual único e aceito por todos, que possa servir de substrato aos modelos de aproximação aos dados empíricos;

- Ainda subsistem preconceitos que identificam a História como uma espécie de saber útil para concursos de conhecimentos gerais na televisão ou ainda para se lembrar de datas e efemérides;

- Em determinadas situações a História escolar é utilizada pelos governos com o objetivo de configurar a consciência dos cidadãos, buscando oferecer uma visão do passado que sirva para fortalecer projetos políticos hegemônicos; 
- Em detrimento da complexidade envolvida no exercício da análise e da explicação de fenômenos históricos, os professores de História, em determinados momentos, optam por oferecer uma ideia de História com informações prontas e acabadas. 28

Essas dificuldades não ocultam, porém, a relevância do lugar ocupado pela disciplina de História na Educação Básica, ou ainda, do lugar ocupado pela história em nossas vidas. Estamos mais bem situados com algum conhecimento da história do que com nenhum conhecimento, bem lembrou Peter Lee (2011). Mas isso é pouco, claro, para quem imagina que o conhecimento histórico possa converter-se numa ferramenta poderosa para que os sujeitos se compreendam e compreendam o lugar que habitam no mundo, e que sejam capazes de lutar por um lugar e uma existência melhor.

Talvez ainda estejamos longe de ensinar de modo que os alunos aprendam a pensar historicamente em virtude da sofisticação e das sutilezas aí envolvidas, haja vista que pesar as conexões entre as diferentes formas de acessar as narrativas sobre o passado disponíveis é apenas um dos desafios entre muitos outros igualmente relevantes. Se de fato ainda há muito a fazer no que tange a práticas possíveis que subsidiem um bom trabalho em sala de aula, voltado à aprendizagem histórica e nela interessado, é preciso qualificar os espaços de formação docente a fim de preparar professores capazes de compreender esse grau de dificuldade, e principalmente que não o negligenciem por isso, mas que o tomem como um desafio a ser enfrentado.

\section{NOTAS}

${ }^{1}$ Diário de anotações de aula de Cristiani Bereta da Silva, 11 set. 2012. O curso de História possui 18 bolsistas do Programa institucional de bolsa de iniciação à docência (Pibid/Capes/Udesc) que desenvolvem atividades em duas escolas de Educação Básica da rede pública de Florianópolis (SC), sob a orientação das professoras Cristiani Bereta da Silva e Luciana Rossato e supervisão dos professores bolsistas Marcos Francisco da Silva (Escola Básica Municipal Vitor Miguel de Souza) e Valéria de Oliveira Florentino (Escola Estadual Básica Padre Anchieta).

${ }^{2}$ LEE, Peter. Por que aprender História? Revista Educar, Curitiba, v.42, n.4, p.19-42, 2011. p.24-25.

${ }^{3}$ RÜSEN, Jörn. Como dar sentido ao passado: questões relevantes de meta-história. Revista História da Historiografia, n.2, p.163-209, mar. 2009. p.165-168. 
${ }^{4}$ SCHMIDT, Maria Auxiliadora; GARCIA, Tânia Maria Braga. Pesquisas em educação histórica: algumas experiências. Educar em Revista, Curitiba, n. esp., p.11-31, 2006; BARCA, Isabel. Investigação em Educação Histórica: fundamentos, percursos e perspectivas. In: OLIVEIRA, Margarida Dias de et al. (Org.). Ensino de História: múltiplos ensinos em múltiplos espaços. Natal: Ed. UFRN, 2008. p.23-32; LEE, 2011.

${ }^{5}$ BERGMANN, Klaus. A História na reflexão didática. Dossiê História em Quadro-Negro: escola, ensino e aprendizagem. Revista Brasileira de História, São Paulo, v.9, n.19, set. 1989/fev. 1990. p.30-32.

${ }^{6}$ RÜSEN, Jörn. Razão histórica. Teoria da história: os fundamentos da ciência histórica. Brasília: Ed. UnB, 2001.

${ }^{7}$ RÜSEN, Jörn. História viva. Teoria da história: formas e funções do conhecimento histórico. Trad. Estevão de Rezende Martins. Brasília: Ed. UnB, 2007. p.111.

${ }^{8}$ LEE, Peter. Em direção a um conceito de literacia histórica. Revista Educar, Curitiba, n. esp., p.131-150, 2006.

${ }^{9}$ SCHMIDT, Maria Auxiliadora. Cognição histórica situada: que aprendizagem histórica é esta? In: BARCA, Isabel; SCHMIDT, Maria Auxiliadora (Org.). Aprender História: perspectivas da educação histórica. Ijuí (RS): Ed. Unijuí, 2009. p.40.

${ }^{10}$ TARDIF, Maurice. Saberes docentes e formação profissional. Petrópolis (RJ): Vozes, 2002. p.16.

${ }^{11}$ MONTEIRO, Ana Maria. Professores de história: entre saberes e práticas. Rio de Janeiro: Mauad X, 2007.

${ }^{12}$ Apenas como exemplo, ver: BITENCOURT, Circe. Ensino de história: fundamentos e métodos. São Paulo: Cortez, 2004; e CAIMI, Flávia Eloisa. Por que os alunos (não) aprendem História? Reflexões sobre ensino, aprendizagem e formação de professores de História. Tempo, v.11, n.21, p.17-32, jul. 2006.

${ }^{13}$ CAIMI, Flávia Eloisa. História escolar e memória coletiva: como se ensina? Como se aprende? In: ROCHA, Helenice Aparecida Bastos et al. (Org.). A escrita da história escolar: memória e historiografia. Rio de Janeiro: Ed. FGV, 2009. p.65-79.

${ }^{14}$ Nelson (pseudônimo). Relatório de observação, $1^{\circ}$ ano, turma 126, Instituto Estadual de Educação, 2006.

${ }^{15}$ MEDEIROS, Alexandre Pedro de; NAKAZIMA JUNIOR, Antonio Shigueo; NOGUEIRA, Filipe Gattino; SILVA, Mariana Heck. Evidências do passado: a diversidade de fontes históricas e as múltiplas explicações em História do Brasil construídas pelos estudantes de Ensino Médio do primeiro ano B. UDESC: Relatório de Estágio em História, 2012. p.59.

${ }^{16}$ GENTIL, Flávio Welker Merola; SCHUTZ, Karla Simone Willeman; MARTINS, Mariane. O uso das fontes: investigando a aprendizagem histórica na turma $1^{\circ} \mathrm{D}$ do Colégio de Aplicação. UDESC: Relatório de Estágio em História, 2012. p.36.

${ }^{17}$ ARAÚJO, Thiago Oliva Lima de. O cinema como instrumento didático no ensino de His- 
tória. In: OLTRAMARI, Arthur Rebonatto et al. Os movimentos populares e a cidadania no Brasil: revoltas no Brasil República. UDESC: Relatório de Estágio em História, 2011. p.85.

${ }^{18}$ CARMO, Catarina Lisboa do; FRANCISCO, Grasiela. Uma Europa nos trópicos? Representações de africanos, afrodescendentes e imigrantes europeus nos discursos histórico, midiático e turístico contemporâneo. UDESC: Relatório de estágio em História, 2012. p.77.

${ }^{19}$ PIERONI, Gabriella Cristina; SILVEIRA Mariana Rotili da; OLIVEIRA, Renan Ritzmann de. A história vai ao cinema: narrativas fílmicas em sala de aula. UDESC: Relatório de Estágio em História, 2011. p.9.

${ }^{20}$ MEDEIROS et al., cit. UDESC: Relatório de estágio em História, 2012. p.17.

${ }^{21}$ SCHUTZ, Karla Simone Willeman. Imagem e biografia: problematizando o uso de imagens e de personagens históricos em sala de aula. In: GENTIL et al., cit. UDESC: Relatório de Estágio em História, 2012. p.131-132.

${ }^{22}$ HALLDÉN, Ola. Conceptual change and the learning of history. International Journal of Educational Research, v.27, n.3, p.201-210, 1997.

${ }^{23}$ KLANN, Carlos José; MELO, Mateus Cavalcanti; BOEING, Rafael Antônio Motta. Construindo representações: a formação do conhecimento histórico dos alunos acerca das identidades no Brasil do século XIX. UDESC: Relatório de Estágio em História, 2010. p.61.

${ }^{24}$ LUNARDELLI, Daniel Henrique França; MARQUES, Fabiane Gabriela Lubian; AQUINO, Mariana Gonçalves de. Entre revoluções e cotidianos. UDESC: Relatório de Estágio em História, 2012. p.114.

${ }^{25}$ ARAÚJO, Thiago Oliva Lima de. O Cinema como instrumento didático no ensino de História. In: OLTRAMARI et al., cit. UDESC: Relatório de Estágio em História, 2011. p.85.

${ }^{26}$ LAVILLE, Christian. Em educação histórica, a memória não vale a razão! Educação em Revista, Belo Horizonte, n.41, p.13-41, jun. 2005. p.15.

${ }^{27}$ SILVA, Cristiani Bereta da. O ensino de História - Algumas reflexões do Reino Unido: entrevista com Peter J. Lee. Tempo e Argumento, Revista do Programa de Pós-Graduação em História da Udesc, Florianópolis, v.3, n.2, p.216-250, jul.-dez. 2012. Disponível em: www.revistas.udesc.br/index.php/tempo/article/view/2175180304022012216; Acesso em: 20 jan. 2013.

${ }^{28}$ PRATS, Joaquín. Ensinar História no contexto das Ciências Sociais: princípios básicos. Revista Educar, Curitiba, Especial, p.191-218, 2006. p.205.

Artigo recebido em 20 de dezembro de 2012. Aprovado em 14 de abril de 2013. 